\title{
The Protective and Therapeutic effect of Antioxidants in the Blueberry Plant on the Liver of Rats Treated with Nicotine
}

\author{
${ }^{1}$ Mahasen Falatah, ${ }^{2}$ Hayat Ismail and ${ }^{3}$ Haleema Al Nahari \\ ${ }^{1}$ Department of Biological Sciences, Faculty of Sciences, King Abdul-Aziz University, P.O. Code 2562, Jeddah, Kingdom of Saudi Arabia. \\ ${ }^{2}$ Department of Biological Sciences, Faculty of Sciences, King Abdul-Aziz University, P.O. Code40648, Jeddah, Kingdom of Saudi Arabia. \\ ${ }^{3}$ Department of Biological Sciences, Faculty of Sciences, King Abdul-Aziz University, P.O. Code 21589, Jeddah, Kingdom of Saudi Arabia.
}

Correspondence Author: Mahasen Falatah, Department of Biological Sciences, Faculty of Sciences, King Abdul-Aziz University, P.0. Code 2562, Jeddah, Kingdom of Saudi Arabia.

Received date: 23 June 2018, Accepted date: 30 August 2018, Online, Online date: 22 September 2018

Copyright: (c) 2018 Mahasen Falatah et al., This is an open-access article distributed under the terms of the Creative Commons Attribution License, which permits unrestricted use, distribution, and reproduction in any medium, provided the original author and source are credited.

\begin{abstract}
Nicotine is a highly toxic organic substance that is responsible for the harmful effects of smoking on health. It causes oxidative stress to contain many harmful free radicals that have negative effects that lead to changes in the function and composition of cells and damage them and are responsible for the harmful effects of smoking on Liver because it is the main site of the metabolism resulting in many negative physiological effects and blueberry plant contains a large number of important natural antioxidants with health benefits, which have the ability to remove free radicals such as polyphenols, which is the strongest Such as polyphenols, which is one of the strongest antioxidants, which is characterized by its ability to protect the components of the cell from the damage of oxidative stress and the prevention of dangerous diseases on human health, such as liver diseases, heart and blood vessels and osteoporosis and diabetes. The aim of this study was toinvestigate the protective and therapeutic effect of antioxidants in the blueberry plant against nicotine damage on liver function and some biochemical measurements with the study of histological changes of the liver. The results showed a significant increase in ALT, LDH level in the nicotine treatment group and a significant decrease in ALT, AST, and LDH enzymes level in the therapeutic and preventive groups. It also showed a breakdown and damage in hepatocytesresult in nicotine treatment and showed improvement result to treatment with plant extract Blueberries. The results of the current study indicated that antioxidants in blueberry extract have protective and therapeutic effects on the liver, which is affected by oxidative stress due to nicotine treatment. Therefore, it is recommended to be used as a herbal medicine to treat liver diseases caused by oxidative stress.
\end{abstract}

Key words: Nicotine, Blueberry, Natural antioxidant, Oxidative stress, Free radicals.

\section{INTRODUCTION}

Smoking causes a wide range of serious diseases affecting the organs of the human body, especially the liver, which performs many important Physiological processes such as treatment of drugs, alcohol and other toxins to eliminate them outside the body Because cigarette smoke contains the large numbers of free radicals that cause and increase the incidence of oxidative stress damage. Also, because nicotine is a highly toxic organic compound and is responsible for the harmful effects of smoking. It affects a variety of cellular processes including alteration of gene expression. Exposure to nicotine also results in oxidative stress and thus damage to the tissues and organs of the body, particularly liver damage because it is the main site of nicotine metabolism and therefore negatively affects its physiological functions [1,2].

The negative effects of cigarette smoking on liver function are reflected the secretion of hepatic enzymes in the serum because it contains many harmful chemicals and toxic compounds that cause liver cell damage, thus increasing the risk of chronic inflammation, liver disease and raising the risk of liver cancer $[3,4]$.

Blueberry (Vaccinium corymbosum L.) is characterized by a number of important natural antioxidants such as Polyphenols, one of the most powerful antioxidants, made up of a large class of chemicals found in plants. It has attracted a lot of attention because of its properties, which gave great hope that it would have beneficial health effects when taken as inputs or supplements also have the ability to remove free radicals. In addition, research has recently proven that it is antibacterial, viral and fungal. A series of clinical studies have also demonstrated the effectiveness of some antioxidants in the treatment of patients with various liver diseases such as hepatitis, hepatic liver disease, and cirrhosis. For antioxidants in patients who have been treated by them [5,6,7,8,9]. Anthocyanin, an important antioxidant in blueberries, is characterized by its anti-aging properties, a major factor in chronic liver disease. Also, Anthocyanin has been shown to be highly effective in increasing the biological age of liver cells. It has therefore been widely used in the field of health products to slow deterioration associated with liver function and structure by inhibiting DNA proliferation [10]

\section{Materials And Methods}

First: Materials:

1-Animals experiment:

The adult rats of the Albino Rats were 50 rats with weights ranging from 120-200 grams. They were divided into 4 groups as follows: 1 . The Control group containing 15 rats given physiological solution daily for 6 weeks. 2 . The Treatment with nicotine group containing 15 rats. Inject $2.5 \mathrm{mg} / \mathrm{kg}$ daily. 3 - The 
Citation: 1Mahasen Falatah, 2018. The Protective and Therapeutic effect of Antioxidants in the Blueberry Plant on the Liver of Rats Treated with Nicotine. Advances in Environmental Biology., 12(9): 1-7.

therapeutic group containing 10 rats injected with nicotine dose of $2.5 \mathrm{mg} / \mathrm{kg}$ per day for two weeks and then was given blueberry extract a dose of $10 \mathrm{mg} / \mathrm{kg}$ daily for 4 weeks. 4-The preventive group containing 10 rats were given the blueberry extract dose of $10 \mathrm{mg} / \mathrm{kg}$ per day for two weeks and then treated with nicotine dose of $2.5 \mathrm{mg} / \mathrm{kg}$ daily for 4 weeks. The study lasted six weeks in an environment where adequate environmental conditions of temperature, humidity, ventilation, lighting , and supply were available, containing all nutrients and provided clean drinking water.

\section{Nicotine:}

Nicotine was used as a yellowish liquid and was given to animals with a dose of $2.5 \mathrm{mg} / \mathrm{kg}$ of body weight by injecting intraperitoneal [11,12].

3 - extract blue berries intentions:

Use blueberry extract, a powder that is dissolved in distal water and then given to animals with a dose of $10 \mathrm{mg} / \mathrm{kg}$ orally [13]

Second: Methods:

1 - Method of collecting samples:

Samples were taken periodically every two weeks from the second week until the end of the sixth week in the following manner:

1 - The number of animals to be sampled and the total number of 50 rats with 5 animals from each group is numbered.

2 - Samples were taken from the control group and treated with nicotine from the second week to the sixth week. While samples were taken from the preventive and therapeutic groups in the sixth week of the study.

3 - Blood samples were taken before slaughter through the eye and collected in special tubes, yellow color of $15 \mathrm{ml}$ free of any anticoagulants for the serum, which was separated by the centrifuge at $300 \mathrm{rpm}$ for 15 minutes and then The serum was distributed in small glass vials for each animal and kept in the freezer at $-18{ }^{\circ} \mathrm{C}$ to be used to measure the level of liver enzymes.

4 .The animal was then slaughtered and dissected to obtain the liver and then preserved in neutral formalin solution until the tissue sections were worked.

2 - biological study: and included each of the following: Measurement of body weight - measuring the weight of the liver - measuring the proportion of the weight of the liver of the body.

3 - Physiological study: The measurement of the level of the following enzymes in the serum: Aspartate aminotransferase (AST) -Alanine aminotransferase (ALT) -Lactate dehydrogenase (LDH).

4 - Histological study: The study of tissue on the liver over a period of six weeks and the study included cross sections of the liver using the dye of hematoxylin and eosin.

5. Statistical analysis: The mean of the mean for the control group and the treatment groups was computed and the standard deviation of S.D was calculated.The TTest was performed at a significant level of $5 \%[14,15]$.

Results:

1-the results of body weight and weight of the liver and the proportion of liver weight of the body.

Table 1: The Protective and therapeutic role of Blueberry $(10 \mathrm{mg} / \mathrm{kg})$ on Body weight $(\mathrm{g})$, Liver weight $(\mathrm{g})$ and Liver relative weight (\%) of adult male rats .

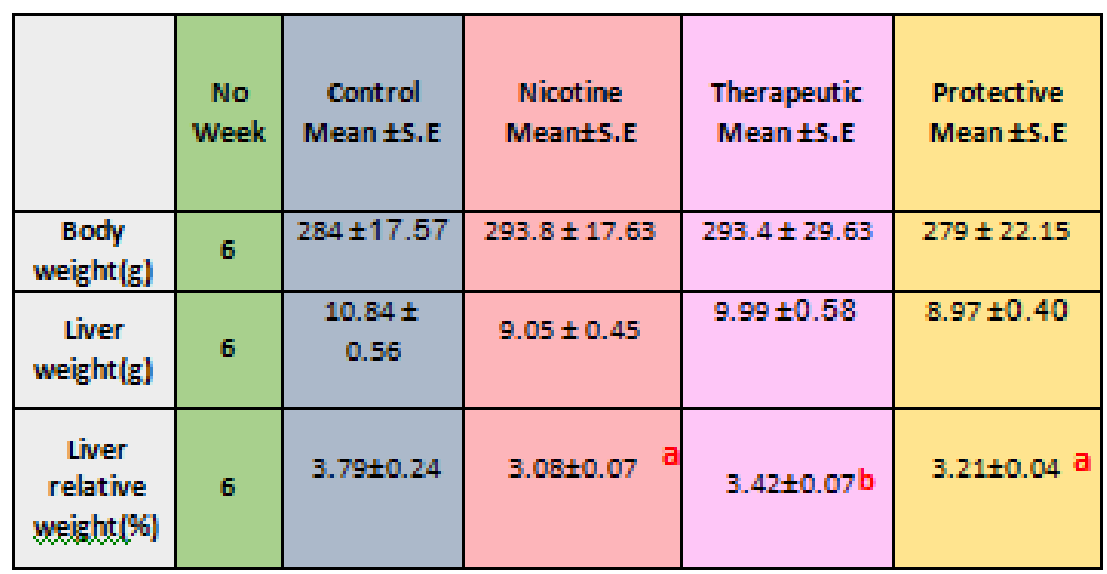

Statistical analyses were performed between control $(\mathrm{C}=5)$ and treated $(\mathrm{T}=5)$ animals by

using .

a: Statistically significant ( $p<0.05$ ) compared to control .

b: Statistically significant (pc0.05) compared to nicotine.

Therapeutic : 2 weeks of Nicotine followed by 4 weeks of Blueberry.

Protective : 2 weeks of Blueberry followed by 4 weeks Nicotine.

Table (1) and Figures (1-1), (1-2) and (1.3) show the therapeutic and protective effect of the antioxidants in the blueberry extract given orally by a dose of 10 $\mathrm{mg}(\mathrm{Kg})$, liver weights $(\mathrm{g})$, and relative weight to body $(\%)$ in adult male rats. The statistical analysis of the experimental measurement values shows the following:

Table (1) and Figure (1-1) show the therapeutic and prophylactic effect of the antioxidants in blueberry plant extract against nicotine damage on body weight in male adult rats.

No body weight effect was observed in all groups at all periods of study.

2 .Table (1) and Figure (1-2) show the therapeutic and protective effect of antioxidants in the blueberry plant extract against nicotine damage on liver weight in male adult rats.

No liver effect was observed in all groups during all study periods.

Table 1 and Figure 1.3 show the therapeutic and protective effect of antioxidants in blueberry extract against nicotine damage on relative weight to body in adult male rats.

There was a significant decrease in the weight of the liver in the group treated nicotine in the sixth week when compared to the control group. 
Citation: 1Mahasen Falatah, 2018. The Protective and Therapeutic effect of Antioxidants in the Blueberry Plant on the Liver of Rats Treated with Nicotine. Advances in Environmental Biology., 12(9): 1-7.

There was also a significant increase in the weight of the liver of the body in the group that represents the therapeutic role in the sixth week when compared to the group treated with nicotine.

There was also a significant decrease in the weight of the liver in the group that represents the protective role in the sixth week when compared to the control group.
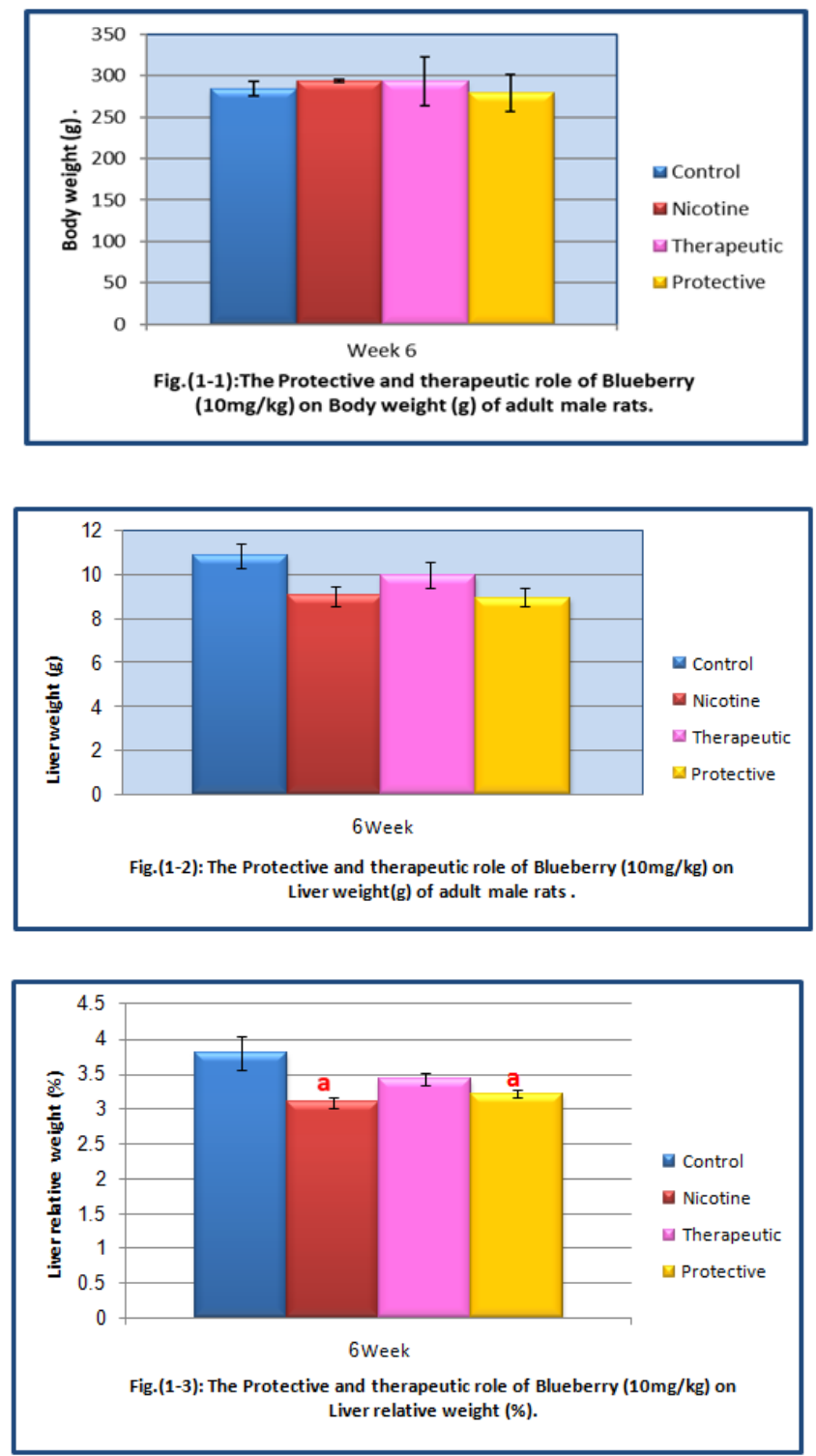

2-Results of hepatic enzymes:

Table (2) and Figures (2.1), (2.2) and (2.3) show the protective and therapeutic effect of the antioxidants in the blueberry extract given orally by a dose of 10 mg (U / L), Aspartate Amino Transferase (AST) (U / L), Lactate Dehydrogenase (LDH) (U / L) in adult male rats. The statistical analysis of the values of the experiment measurements shows the following:

Table (2) and Figure (2-1) show the protective and therapeutic effect of the antioxidants in the extract of berry plant against the damage caused by a substance on the enzyme Alanine Aminotransferase (ALT).

There was a significant increase in the nicotine treatment group in the sixth week when compared to the control group.

A significant decrease was observed in both the treatment group and the protective role group in week 6 when compared with both the control group and the nicotine- treated group.

Table 2 and Figure 2-2 show the protective and therapeutic effect of the antioxidants in blueberry plant extract against nicotine damage on the Aspartate Amino Transferase (AST).

There was a significant decrease in both the nicotine treatment group and the group representing the therapeutic role and the group that represents the protective role in the sixth week when compared with the control group.

3-Table (2) and Figure (2-3) show the protective and therapeutic effect of the antioxidants in blueberry plant extract against nicotine damage on Lactate Dehydrogenase (LDH).

There was a significant increase in the nicotine treatment group in the sixth week when compared to the control group.

There was also a significant decrease in the group representing the therapeutic role in the sixth week when compared with both the control group and the group treated with nicotine

There was also a significant decrease in the group that represents the protective role in the sixth week when compared to the group treated with nicotine. 
Citation: 1Mahasen Falatah, 2018. The Protective and Therapeutic effect of Antioxidants in the Blueberry Plant on the Liver of Rats Treated with Nicotine. Advances in Environmental Biology., 12(9): 1-7.

Table 2: The Protective and therapeutic role of Blueberry $(10 \mathrm{mg} / \mathrm{kg}$ ) on Aspartate Aminotransferase (AST) (U/L), Lactate Dehydrogenase(LDH)(U/L), Alanine Aminotransferase (ALT)(U/L) of adult male rats.

\begin{tabular}{|c|c|c|c|c|c|}
\hline & $\begin{array}{c}\text { No } \\
\text { Week }\end{array}$ & $\begin{array}{c}\text { Control } \\
\text { Mean } \pm \text { S.E }\end{array}$ & $\begin{array}{c}\text { Nicotine } \\
\text { Mean } \pm \text { S.E }\end{array}$ & $\begin{array}{c}\text { Therapeutic } \\
\text { Mean } \pm \text { S.E }\end{array}$ & $\begin{array}{c}\text { Protective } \\
\text { Mean } \pm \text { S.E }\end{array}$ \\
\hline $\begin{array}{c}\text { Alanine } \\
\text { Aminotransferase } \\
\text { (ALT)(U/L) }\end{array}$ & 6 & $95.8 \pm 0.48$ & $97.4 \pm 0.24^{\mathrm{a}}$ & $90.6 \pm 1.12^{\mathrm{a} . \mathrm{b}}$ & $92.4 \pm 0.97$ \\
\hline $\begin{array}{c}\text { Aspartate } \\
\text { Aminotransferase } \\
\text { (AST) (U/L) }\end{array}$ & 6 & $100.4 \pm 2.11$ & $88.2 \pm 3.32^{\mathrm{a}}$ & $84 \pm 2.38$ a & $87.6 \pm 2.01^{\mathrm{a}}$ \\
\hline $\begin{array}{c}\text { Lactate } \\
\text { Dehydrogenase } \\
\text { (LDH)(U/L) }\end{array}$ & 6 & $440 \pm 22.33$ & $709 \pm 59.10^{\mathrm{a}}$ & $308.4 \pm 50.64^{\mathrm{a}}$ & $\mathrm{b}$ \\
$436.7 \pm 45.66^{\mathrm{b}}$ \\
\hline
\end{tabular}

Statistical analyses were performed between control $(\mathrm{C}=5)$ and treated $(\mathrm{T}=5)$ animals by using .

a: Statistically significant $(p<0.05)$ compared to control .

b: Statistically significant $(p<0.05)$ compared to nicotine

Therapeutic : 2 weeks of Nicotine followed by 4 weeks of Blueberry .

Protective : 2 weeks of Blueberry followed by 4 weeks Nicotine
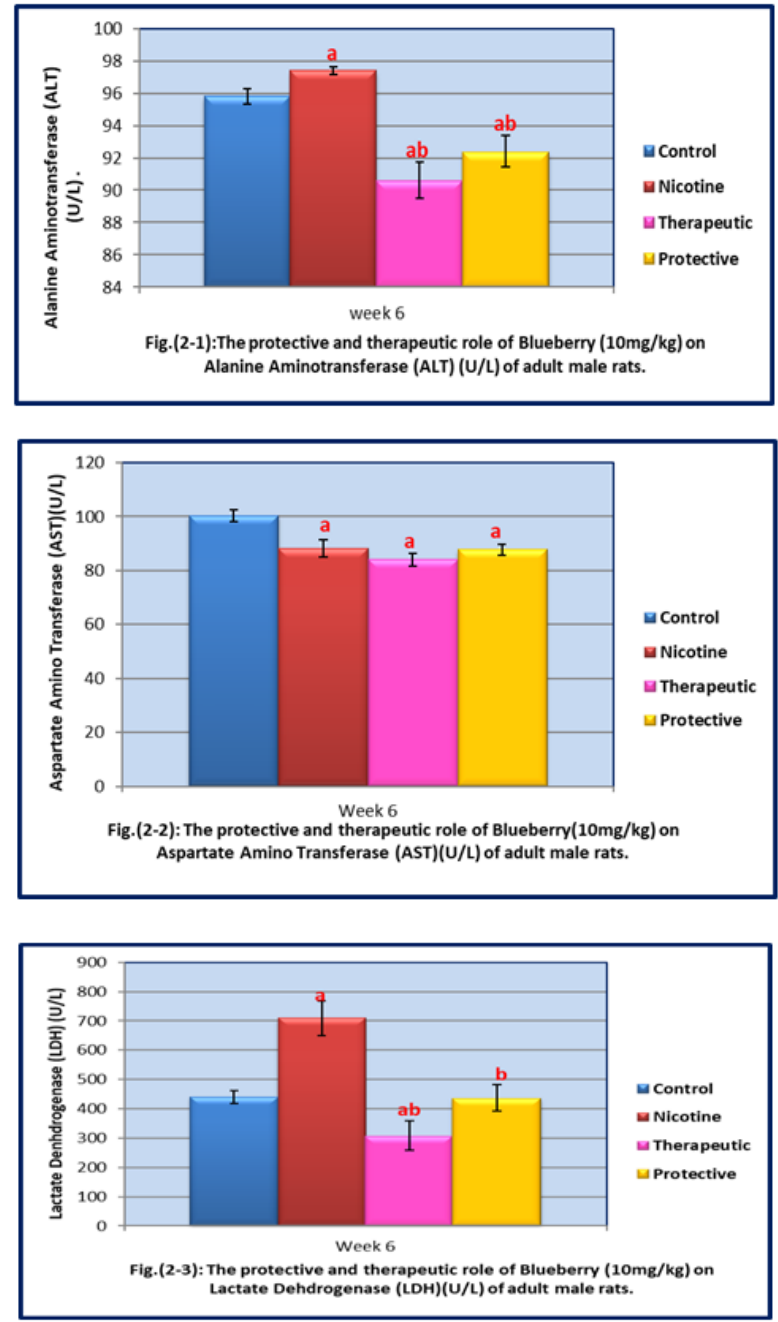

Results of Histological Study:

Discussion:

1 - Adverse effects of nicotine on body weight, liver weight, body weight and the role of blueberry extract in reducing its effects:

The results of the current study show a significant decrease in the weight of the body in the group treated nicotine in the sixth week when compared to the control group. This is consistent with what $[16,17,2]$ suggest that nicotine causes a decrease in liver weight as they explain that it is due to metabolic disorders in rats due to the effect of nicotine and consequently loss of liver weight and also due to changes Histological and liver damage caused by nicotine treatment.

2 - the harmful effects of nicotine on the liver and its functions and the role of blueberry plant in reducing its effects:

2.1Liver enzymes:

The results of the present study showed a significant increase in ALT, LDH in the nicotine treatment group in the sixth week when compared to the control group. According to the study conducted by [18], the high and increasing activity of enzymes is due to the fact that cigarette smoke contains a large variety of 
compounds including nicotine, tar, carbon monoxide, as well as many oxidizing substances and free radicals[19]. Which causes oxidative stress, an imbalance between free radicals and antioxidants in the blood and tissues of smokers, leading to damage and destruction of hepatic cells and the release of enzymes in the circulatory system [20.21] that the liver injury by oxidative stress lead to an increase in the level of the enzyme This is due to the low activity of hepatic antioxidant enzymes.

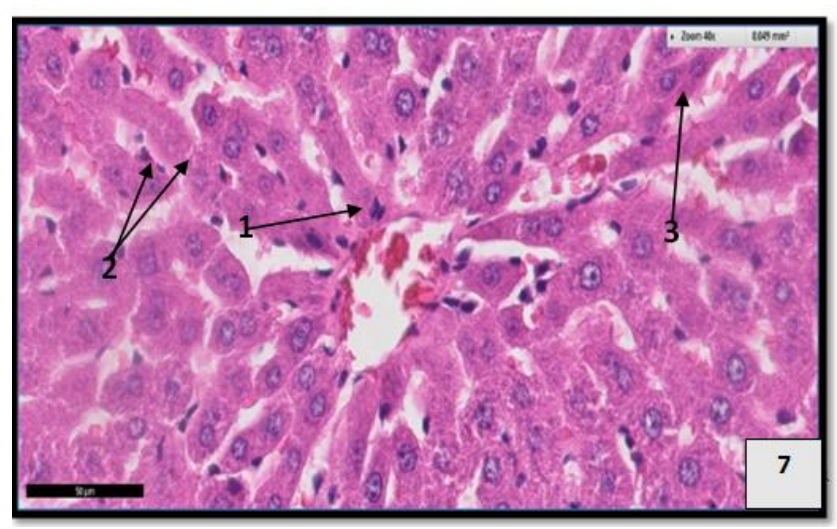

Fig. 7: A transvers section in rat liver from the control group that shows normal liver structure: 1-Central vein.2-Hepatic Liver Cells.3-Hepatic tapes' 40, H and E.

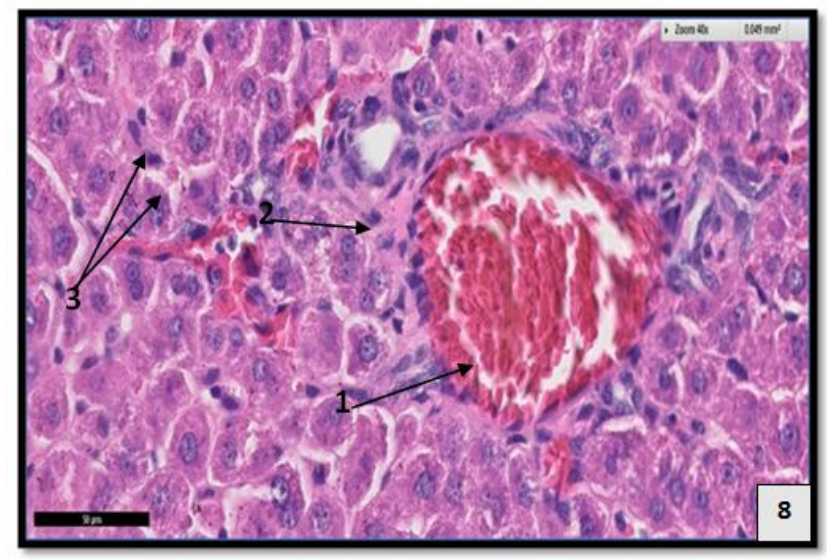

Fig. 8: A transvers section in rat liver from the Nicotine group that shows Abnormal liver structure: 1-Severe bleeding in the portal vein.2-Deformation of bile duct and pylori area components.3-Necrotic decomposition of hepatic cell nucleiAnd hepatic tissue breakdown..X 40, H and E.

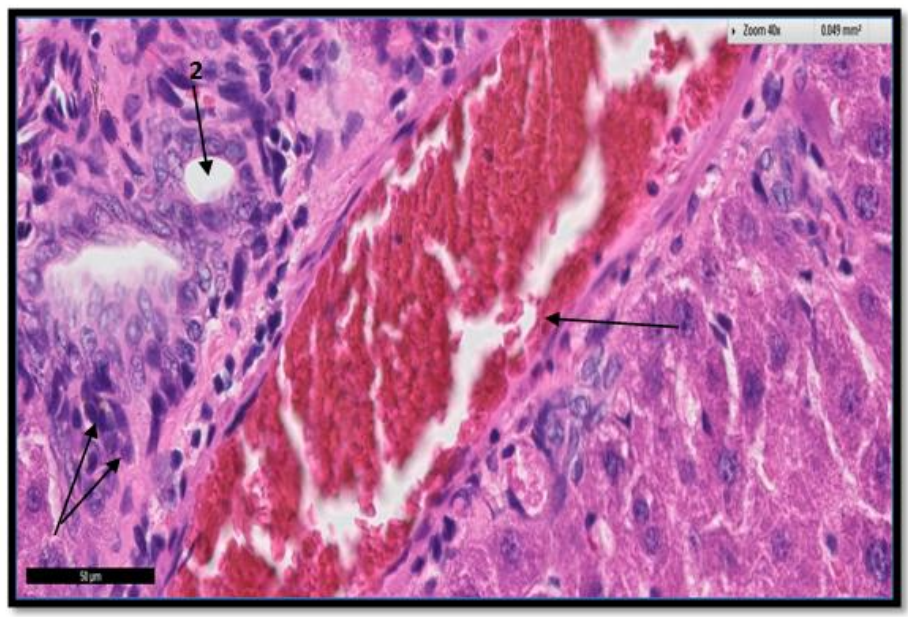

Fig. 9: A transvers section in rat liver from the Nicotine group that shows Abnormal liver structure: 1-Extend and severe bleeding in the portal vein.2Deformation of bile duct and pylori area components.3-Inflammatory lymphocytes' .X40, H and E. 


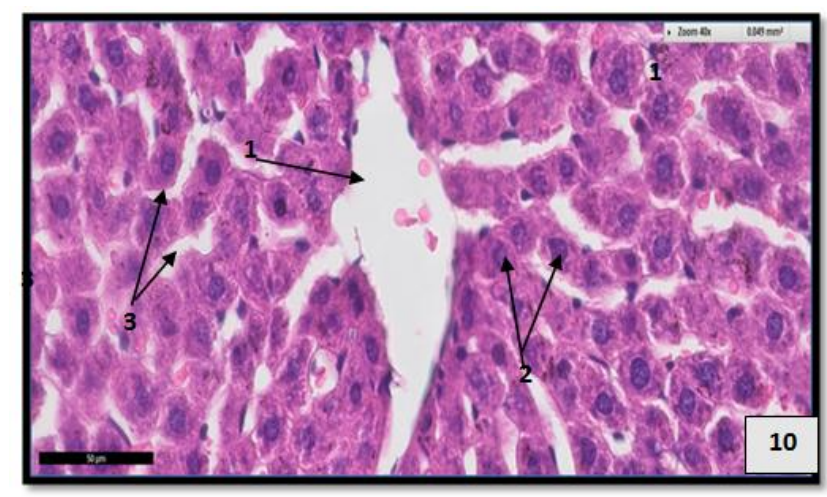

Fig. 10: A transvers section in rat liver from theTherapeutic group that shows: 1-Central vein.2- Most liver cells are intact. 3-Most liver bands are intact, and some are narrow '. X40, $\mathrm{H}$ and $\mathrm{E}$.

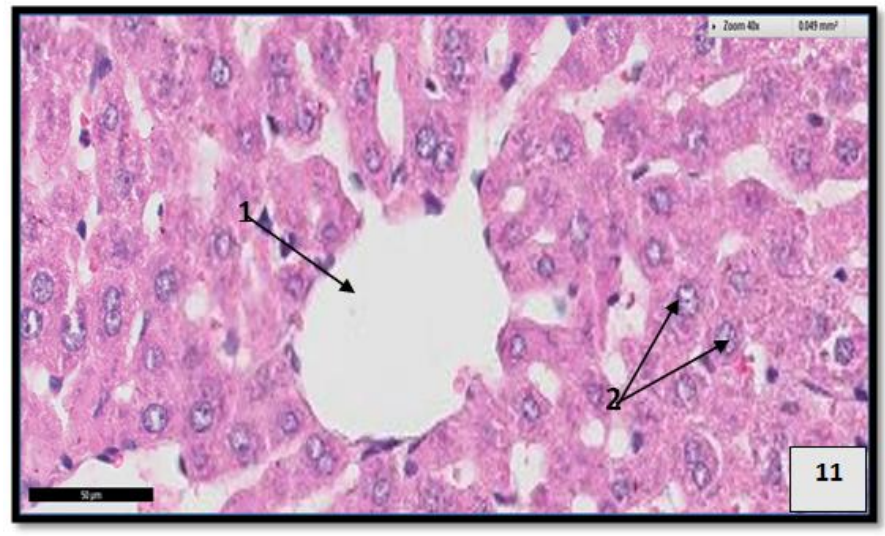

Fig.11: A transvers section in rat liver from thePreventivegroup that shows: 1-Central vein.2-Hepatic Liver Cells and Radiology of hepatic ribbons with the integrity of many cells and nuclei with the appearance of some of them crumbling and decomposing '. X40, H and E.

The results of the present study also showed a significant decrease in AST, ALT, LDH in both the treatment and preventive role group when compared with the control group. There was also a significant decrease in LDH in the treatment group in the sixth week when compared with both the control group and the nicotine treatment group. This is in line with what[22] found that polyphenols caused a significant reduction in the activity of liver enzymes in the blood of rats with liver cancer, explaining that it is due to the ability of polyphenols to reduce the damage caused by The process of oxidation due to the free radicals found in the liver. Also Polyphenol has reduced the levels of liver enzymes in the serum and protect the liver of rats from fibrosis by maintaining the integrity of the plasma membrane and thus suppress the leakage of enzymes to the circulation.

$[23,24]$ reported that polyphenols prevented large increases in ALT-AST-LDH levels in the serum indicating that they maintained the structural and functional integrity and also protection Liver tissue is damaged against oxidative stress because it stimulates the action of antioxidants enzymatic.

\subsection{Histological composition of the liver:}

The results of the present study show that hepatocellular carcinoma, liver fat accumulation, the appearance of fibroblasts, atrophy of the nucleus, hemorrhage, and vascular expansion are consistent with the study by[25] The deposition and accumulation of fat in liver cells, causing toxicity and damage to cells Liver. [26] found that smoking causes hepatocellular hematopoiesis and the destruction of the lining of the liver's bile ducts. These abnormalities affect the integrity of liver function.

The histological sectors of the liver treated with blueberry extract and nicotine together in the preventive and therapeutic groups showed improvement of hepatic tissue and hepatic cells. This is consistent with the study of $[27,28]$ found that blueberry plant had protective effects against liver damage. [28]found that mitochondria were the main target of the protective effect of blueberry, where it stopped the reactive oxygen that causes the destruction of mitochondria and improved the electron transport chain and improved mitochondrial membrane.[29]also reported that blueberries improve the pathological changes in the liver tissue caused by $\mathrm{CCL}^{4}$. The antioxidant has a positive effect on hepatic stellate cells during liver injury by cirrhosis in $\mathrm{CCL}^{4}$-treated mice. Decreased rate of cell death in the treated group with anthocyanin [29].

\section{Conclusion:}

The blueberries of plants containing high-strength antioxidants containPolyphenols, anthocyanin, and phenolic compounds. The results of the current study indicate that these antioxidants have preventive and therapeutic effects on liver enzymes and their histological structure against oxidative stress damage caused by treatment with Nicotine because of its biological activity and ability to remove the roots and raise the level of antioxidant enzyme in the body, which leads to the treatment of damage and damage caused by oxidative stress in liver cells. Therefore, this study recommends the use of blueberry extract as a herbal medicine for the treatment of liver diseases caused by oxidative stress, where treatment with natural antioxidants to stop the start of the development of liver diseases and is safe and have no side effects. It is also recommended to treat the fruit and blueberry juice through the diet for the important role of natural antioxidants in supporting and strengthening the self-oxidizing antioxidants produced by the body to resist and treat the dangerous diseases resulting from oxidative stress. That the results of this study can provide information that contributes to the support and development of alternative medicine research in the field of treatment using natural antioxidants, especially that there is a large global trend to study the use of natural antioxidants in the treatment of liver diseases and also develop blueberry cultivation programs to improve its productivity and nutritional aspects, For example, it can promote and increase its important natural antioxidant. In the future physiological studies, the results of this study will be studied by studying the effect of multiple doses of blueberry extract over longer periods to determine the most effective and effective therapeutic and preventive doses in the treatment of liver diseases caused by oxidative stress. The study will also study the therapeutic and preventive mechanisms of antioxidants Natural in Blue Berries that works in the treatment and prevention of liver diseases. 


\section{REFERENCES}

[1] Husen, P.O., R.A. Ahmed, K.M. Ahmed, I.D. Abdulla, H.M. Ayub and S.H. Hamad, 2015. Cigarette Smoking Risks on Blood Indices and Liver Enzymes of Male and Female Smokers in Kurdistan, Iraq, 8(3): 227-230.

[2] Salahshoor, M., S. Mohamadian, S. Kakabaraei, S. Roshankhah, C. Jalili, 2016. Curcumin improves liver damage in male mice exposed to nicotine. Journal of Traditional and Complementary Medicine, 6(2): 176-183.

[3] Karl, R.O., D.C. Johnson, 2010. Gluten Intolerance. Elevated Liver Enzymes and Liver Damage. Eur Rev Med Pharmacol Sci.,14: 567-572.

[4] Jabbar, D.K., 2017. Cigarette Smoking and Serum Liver Enzymes. Journal of Babylon University/Pure and Applied Sciences, 3-25.

[5] Emerit, I., C.Y. Huang, F. Serejo, P. Filipe, A. Fernandes, A. Costa, Carneiro, M.M. De, 2005. Oxidative stress in chronic hepatitis C: a preliminary study on the protective effects of antioxidant flavonoids. Hepato Gastroenterology, 52(62): 530-536.

[6] Hu, M., 2007. Commentary: Bioavailability of flavonoids and polyphenols: Call to arms. Molecular Pharmaceutics, 4(6): 803-806.

[7] Fraga, C.G., 2007. Plant polyphenols: How to translate their in vitro antioxidant actions to in vivo conditions. In IUBMB Life, 59: 308-315.

[8] Esrefoglu, M., 2012. 'Oxidative stress and benefits of antioxidant agents in acute and chronic hepatitis',Hepatitis Monthly, 160-167.

[9] Bingül, I., C. Başaran-Küçükgergin, A.F. Aydln, M. Soluk-Tekkeşin, V. Olgaç, S. Doğru-Abbasoğlu and M. Uysal, 2016. Blueberry treatment attenuated cirrhotic and preneoplastic lesions and oxidative stress in the liver of diethylnitrosamine-treated rats. International Journal of Immunopathology and Pharmacology, 29(3): 426-437.

[10] Wei, J., G. Zhang, X. Zhang, D. Xu, J. Gao and J. Fan, 2017. Anthocyanins Delay Ageing-Related Degenerative Changes in the Liver. Plant Foods for Human Nutrition, 72(4): 425-431.

[11] Gawish, M.A., S. Ramadan, A.M. Hassan, M.A. Issa, 2010. Morphometrical, Histopathological, and Cytogenetical Ameliorating Effects of Green Tea Extract on Nicotine Toxicity of the Testis of Rats. Journal of Cytology \& Histology, 1(2).

[12] Lari, P., K. Abnous, M. Imenshahidi, M. Rashedinia, M. Razavi, H. Hosseinzadeh, 2015. Evaluation of diazinon-induced hepatotoxicity and protective effects of crocin. Toxicology and Industrial Health, 31(4): 367-376.

[13] Zepeda, A., L.G. Aguayo, J. Fuentealba, C. Figueroa, A. Acevedo, P. Salgado, J. Farías, 2012. Blueberry extracts protect testis from hypobaric hypoxia induced oxidative stress in rats. Oxidative Medicine and Cellular Longevity

[14] Arkin, H. and R.R. Colton, 1963. Tables for statistician .New York:Barnes \& Noble.

[15] Hill, M.O., 1973. Reciprocal Averaging: An Eigenvector Method of Ordination. Journal of Ecology, 61(1): 237-249.

[16] Latif, A.A., M. Mansha, S. Sharif, S. Saeed, T. Gill, K. Saif, T. Farasat, 2013. Study of histological changes in liver, lungs and testes of dermally nicotine treated albino mice. Medical Forum Monthly, 24(8): 59-63.

[17] Ebrahimi, S., H. Sadeghi, A. Pourmahmoudi, Z. Tabeshfar, 2015. Protective Effect of Zizphus Vulgaris Extract, on Liver Toxicity in Laboratory Rats. Biomedical and Pharmacology Journal, 8(2): 779-784.

[18] Hamad, A., K. Al-kubaisy, S. Al-daline and F. Ai-ani, 2015. Effect of cigarets smoking on serum and salva liver enzymes function .Europena journal of biomedical and phamceutical sciences.

[19] Richmond, J., 1979. "Smoking and Health". MI. U. S. Government Printing Office. New York, 49.

[20] Chan-Yeung, M., P. Ferreira, J. Frohlich, M. Schulzer, F. Tan, 1981. The effects of age, smoking, and alcohol on routine laboratory tests. Am J Clin Pathol, 75(3): 320-326.

[21] Cui, B.K., S. Liu, S.H. Li, J. Wang, Q.B. Wang, S.P. Li, X.J. Lin, 2012. Effect of tea polyphenol on oxidative injury in S180 cells induced hepatocarcinoma mice. International Journal of Molecular Sciences, 13(5): 5571-5583.

[22] El-Beshbishy, H.A., O.M. Tork, M.F. El-Bab, M.A. Autifi, 2011. Antioxidant and antiapoptotic effects of green tea polyphenols against azathioprine-induced liver injury in rats. Pathophysiology: The Official Journal of the International Society for Pathophysiology / ISP.

[23] Ding, Q., Y. Li, Xu, 2016. "Attenuating oxidative stress by paeonol protected against acetaminophen-induced hepatotoxicity in mice," PLoS One, 11-5. article e 0154375 ,

[24] Wu, H., G. Zhang, L. Huang, H. Pang, N. Zhang, Y. Chen and G. Wang, 2017. Hepatoprotective Effect of Polyphenol-Enriched Fraction from Folium Microcos on Oxidative Stress and Apoptosis in Acetaminophen-Induced Liver Injury in Mice. Oxidative Medicine and Cellular Longevity, 1-14.

[25] Iranloye, B.O., A.F. Bolarinwa, 2009. Effect of nicotine administration on weight and histology of some vital visceral organs in female albino rats. Nigerian Journal of Physiological Sciences, 24(1): 7-12.

[26] Adedayo, A.D., A.A. Tijani, A.A. Musa, T.D. Adeniyi, 2011. Histological study of smoke extract of Tobacco nicotiana on the heart, liver, lungs, kidney, and testes of male Sprague-Dawley rats. Nigerian Medical Journal, 52(4): 217-222.

[27] El-Gengaihi, S.E., M.A. Hamed, A.E.R.M. Khalaf-Allah, M.A. Mohammed, 2013. Golden berry juice attenuates the severity of hepatorenal injury. Journal of Dietary Supplements, 10(4): 357-369.

[28] Zhao, M., X. Liu, Y. Luo, H. Guo, X. Hu, F. Chen, 2015. Evaluation of Protective Effect of Freeze-Dried Strawberry, Grape, and Blueberry Powder on Acrylamide Toxicity in Mice. Journal of Food Science, 80(4): H869-H874.

[29] Zhan, W., X. Liao, T. Tian, L. Yu, X. Liu, B. Li, Q. Yang, 2017. Study on the effects of blueberry treatment on histone acetylation modification of CCl4induced liver disease in rats.Genetics and Molecular Research, 16(1). 